\title{
THE PRESENT SITUATION OF HUMAN CRYPTOSPORIDIASIS IN SOME CENTERS IN DAKAHLIA GOVERNORATE, EGYPT
}

\author{
By \\ Gamal A. Abo-Sheishaa \\ Department Of Parasitology, Faculty of Medicine, Al-Azhar University
}

\begin{abstract}
Background : Cryptosporidiosis is a zoonotic disease transmitted by the feco-oral route and results from the ingestion of Cryptosporidium spp. oocysts through the consumption of fecally contaminated food or water or through direct person-to-person or animal-to-person contact. Infection by the parasite accounts for up to $6 \%$ of all diarrheal diseases in immunocompetent patients, and presents in up to $24 \%$ of persons with both AIDS and diarrhea worldwide. In the literature, the prevalence of Cryptosporidium infection in Egypt varied significantly from $0 \%$ to $47 \%$
\end{abstract}

Objective: The aim of the work was to assess the problem of cryptosporidiosis in some centers in Dakahlia Governorate, Egypt.

Subjects and Methodology: A total of 1786 individuals of different ages and both sexes were chosen randomly from May 2012 to August 2014 from rural and urban areas. All cases were subjected to history taking, clinical examination and laboratory investigations. Fecal specimens were examined by direct smear and concentration techniques using both formol-ether concentration and sheater's flotation methods. Microscopic examination of modified Ziehl-Neelsen, and aurmaine stained stool smears were also done as well as detection of coproantigens using ELISA technique .

Results: Out of 1786 collected stool samples from four centers, i.e. Mansoura, Talkha, Belqas and Aga, only $97(5.43 \%), 109(6.1 \%)$ and $178(9.96 \%)$ were positive according to Ziehl-Neelsen, Auramine and Coproantigen techniques. The highest prevalence of infection was recorded in Talkha center and Coproantigen was the most sensitive technique. Rural areas showed non significant higher prevalence of Cryptosporidiosis, while females showed relatively significant higher infection when using auramine stain. The infection was non significantly higher among the age group less than 5 years. Mixed infections were found in 43 cases ( 39.45\%) and distributed as 22 cases (20.18\%) having one parasite, 11 cases (10.09\%) having two parasites while those infected with more than two parnsites were 10 cases $(9.17 \%)$. Asymptomatic cases represented 15 cases $(22.73 \%)$, while symptomatic cases were 51 cases $(77.27 \%)$ and disributed as having abdominal pain (43 cases-5.15\%), jaundice ( 8 cases-12.12\%), abdominal distesion (39 cases $-59.09 \%$ ), diarrhea (42 cases-63.43\%), tender abdomen (44 cases- $86.27 \%$ ), hepatomegaly (13 cases$25.49 \%$ ), dehydration ( 1 cases- $41.18 \%$ ) and with ascites ( 5 cases- $11.36 \%$ ) .

Conclusion: The high prevelance of Cryptosporidium infection in the studied areas must be taken in mind of laboratory personell and as a routine examination of all diarrhiec samples.

\section{INTRODUCTION}

Cryptosporidium spp. is a coccidian parasite which infects humans and animals (Xiao, 2010). Diarrhea caused by parasites accounts for more than 3.1 million deaths each year among children less than 15 years of age, mostly in developing countries (Colford et al., 
2005).

Cryptosporidiosis causes chronic and life threatening diarrhea among immunocompromised individuals as well as selflimiting diarrhea in immunocompetent individuals (Paul \& Gordon., 2002 and Banwat et al., 2004). Infection by the parasite accounts for up to $6 \%$ of all diarrheal diseases in immunocompetent persons and presents in up to $24 \%$ of persons with both AIDS and diarrhea worldwide (Bialek et al., 2002).

Transmission occurs through the fecooral route, following direct or indirect contact with Cryptosporidium oocysts via person-to-person, zoonotic waterborne, foodborne or airborne contact (Fayer $\boldsymbol{e t}$ al., 2000). In developing countries, the parasite is endemic and significantly associated with moderate-to-severe diarrhea in infants, a finding that highlighten the need to develop resources to diagnose, treat, and prevent cryptosporidiosis in resource-poor settings. Under this situation, routine diagnosis and effective reporting of Cryptosporidium to local and national surveillance organizations remain of key importance in understanding the epidemiology of this important, but often underestimated, pathogen (Caccio and Putignani, 2013).

The impact of Cryptosporidium on children has been demonstrated also in Arab countries such as Egypt, Jordan, Kuwait, Libya, Palestine, Saudi Arabia and Tunisia. Prevalence rates ranged from 1-43 \% (mean $8.7 \%$ ) in diarrheic immunocompetent children, and from 1$82 \%$ (mean $41 \%$ ) in immunocompromised children and adults were reported (Ghenghesh et al., 2012).

In Egypt, Cryptosporidium has been identified as a prevalent and virulent agent of childhood diarrhea in the Nile Delta (Antonios et al., 2001). Methods to detect Cryptosporidium spp. in feces usually involve microscopic examination of stained fecal smears (modified ZiehlNeelsen, safranin methylene blue, auramine phenol), antigen detection (immunofluorescence, enzyme-linked immunosorbent assay [ELISA]), or genome detection (polymerase chain reaction [PCR] amplification of the 185 rRNA gene). Each varies in sensitivity and specificity, and there is no universally accepted "gold standard technique" (Areeshi et al., 2007).

There are big differences in the prevalence of cryptosporidiosis disease. In 19 studies carried out on immunocompetent individuals with diarrheal diseases, the prevalence rate varied between $0 \%$ and $47 \%$ (Youssef et al., 2008). The aim of the present work was to asses the problem of cryptosporidiosis in Dakahlia Governorate, Egypt.

\section{SUBJECTS AND METHODS}

A total of 1786 cases of different ages in both sexes with written consents from them or their gardeners were obtained. Dakahlia Governorate is the largest agricultural district in the Nile Delta, we selected Mansoura city the Capital of Dakahlia Governorate and centers around it to carry out the field and laboratory studies on human Cryptosporidiasis. Four centers were choosen, i.e. Mansoura, Talkha, Aga and Belqas between the period from May 2012 to August 2014. The work was developed in the Department of Parasitology, Al-Azhar Faculty of Medicine.

Cases were randomly taken from rural 
and urban areas, i.e. houses, schools, health units and hospitals. All of them were subjected to :

1- History taking of clinical examination including name, age, sex, occupation, residence, complain taking (if present), nausea, vomiting, dyspepsia, constipation, diarrhea, abdominal distension or enlargement, abdominal tenderness, hepatomegaly, signs of dehydration and ascites.

2- Laboratory examination:

a- Urine examination (Garcia, 2007).

b- Stool examination : Fecal specimens were examined by direct smear or concentrated by both formol-ether concentration and sheater's flotation (Ridley \& Hawgood., 1956 and Markell et al., 1999).

c- Microscopic examination according to modified Ziehl-Neelsen and aurmaine stained smears were done for positive samples ( Paik, 1980)

d- Detection of coproantigens using Ridascreen Cryptosporidium (Art. No: C1201, Lot: 12131 R-Biopharm AG, Darmstadt, Germany according to the manufacturer's method). (Ridley and Hawgood, 1956) .

Statistical analysis: The collected data were organized, tabulated and statistically analyzed using SPSS, version 13 (USA) . For quantitative data, number and percent distribution, the mean and standard deviation were calculated. Chi $\left(\mathrm{X}^{2}\right)$ square was used as a test of significance. Significance was adopted at $\mathrm{P}<0.05$ for interpretation of results of tests of significance.

\section{RESULTS}

Out of 1786 collected stool samples from the four centers, only 97(5.43\%), $109(6.1 \%)$ and $178(9.96 \%)$ were positive according to Ziehl-Neelsen, Auramine and Coproantigen techniques respectively. The difference was significant using $\mathrm{Z} / \mathrm{N}(\chi 2=$ 9.034 and $\mathrm{p}=0.001)$, not significant using ELISA technique $(\chi 2=16.113$ and $p=$ $0.128)$ and Auramine stain $(\chi 2=10.381$ and $p=0.115)$. The highest prevalence of infection was recorded in Talkha center . Non statistically significant difference of prevalence was detected among the centers $\left(\chi^{2}=3.711\right.$ and $\left.p=0.294\right)$, and coproantigen was the most sensitive technique (Table 1). The infection was relatively higher among the age group less than 5 years. The prevalence was significantly higher using Ziehl-Neelsen stain $(\chi 2=9.034, p=0.028)$, Auramine stain $(\chi 2=10.381, \mathrm{p}=0.015)$ and by Coproantigen detection $\left(\chi^{2}=16.113, \mathrm{p}=\right.$ 0.001- Table 2). Females showed relatively significant higher infection when using auramine $\operatorname{stain}(\chi 2=4.046$ and $\mathrm{p}=0.044)$. However, using Coproantigen detection by ELISA and $\mathrm{Z} / \mathrm{N}$ the difference showed no statistical significance $(\chi 2=0.36$ and $\mathrm{p}=0.548)$ and $(\chi 2=7.36$ and $\mathrm{p}=0.321)$ respectively (Table 3). Rural areas showed higher prevalence of infection statistically: The difference was significant using Auramine stain $(\chi 2=7.716$ and $p=0.005$. However, neither by $\mathrm{Z} / \mathrm{N}$ stain nor by ELISA the difference was statistically significant, i.e. $(\chi 2=1.247, p=0.264)$ and $(\chi 2=2.247, p=$ $0.133)$ respectively (Table 4$)$. Mixed infections was found in 43 cases $(39.45 \%)$ and distributed as one parasite in 22 cases $(20.18 \%)$, two parasites in 11 cases $(10.09 \%)$, while those infected with more 
than two parasites were 10 cases $(9.17 \%$ Table 5). Asymptomatic cases represented 15 cases $(22.73 \%)$, while symptomatic cases were 51 cases $(77.27 \%)$, and distributed as having abdominal pain (43 cases- $65.15 \%)$, jaundice (8 cases$12.12 \%$ ), abdominal distesion (39 cases-
$59.09 \%$ ), diarrhea (42 cases- $63.43 \%$ ), tender abdomen (44 cases-86.27\%), hepatomegaly (13 cases-25.49 \%), dehydration (21 cases- $41.18 \%$ ) and ascites (5 cases-11.36\%). The patients complained of more than one symptom and sign (Table 6).

Table (1): Diagnosis of Cryptosporidium cases by Ziehl-Neelsen, Aurmaine and coproantigen (ELISA) in the selected centers.

\begin{tabular}{|l|l|l|l|l|l|}
\hline \multicolumn{1}{|c|}{ Locality } & $\begin{array}{c}\text { Mansoura } \\
\text { Methods }\end{array}$ & $\begin{array}{c}\text { Talkha } \\
(\text { No }=\mathbf{6 6 3})\end{array}$ & $\begin{array}{c}\text { Belqas } \\
(\mathrm{No}=\mathbf{2 9 4})\end{array}$ & $\begin{array}{c}\text { Aga } \\
(\mathrm{No}=\mathbf{3 8 7})\end{array}$ & $\begin{array}{c}\text { Total } \\
(\text { No =1786) }\end{array}$ \\
\hline Ziehl-Neelsen & $17(17.53 \%)$ & $35(36.08 \%)$ & $25(25.77 \%)$ & $20(20.62 \%)$ & $97(5.43 \%)$ \\
\hline Auramine & $20(18.35 \%)$ & $38(34.87 \%)$ & $28(25.69 \%)$ & $23(21.1 \%)$ & $109(6.10 \%)$ \\
\hline Coproantigen & $37(20.79 \%)$ & $54(30.34 \%)$ & $46(25.84 \%)$ & $41(23.03 \%)$ & $178(9.96 \%)$ \\
\hline
\end{tabular}

Table (2): Age distribution of cryptosporidiosis.

\begin{tabular}{|c|c|c|c|}
\hline Age Methods & Ziehl-Neelsen & Auramine & Coproantigen \\
\hline Up to 5 & $26(8 \%)$ & $29(8.92 \%)$ & $42(12.92 \%)$ \\
\hline$>5-20 \quad(566)$ & $34(6.01 \%)$ & $37(6.54 \%)$ & $70(12.37 \%)$ \\
\hline$>20-40(559)$ & $19(3.40 \%)$ & $21(3.76 \%)$ & $34(6.08 \%)$ \\
\hline$>40 \quad(336)$ & $18(5.36 \%)$ & $22(6.55 \%)$ & $32(9.52 \%)$ \\
\hline Total (1786) & $97(5.43 \%)$ & $109(6.10 \%)$ & $178(9.96 \%)$ \\
\hline
\end{tabular}

Table (3): Sex distribution of Cryptosporidiosis.

\begin{tabular}{|c|c|c|c|}
\hline Sex Methods & Ziehl-Neelsen & Auramine & Coproantigen \\
\hline Male(912) & $52(5.70 \%)$ & $44(4.82 \%)$ & $85(9.32 \%)$ \\
\hline Female (874) & $45(5.15 \%)$ & $65(7.44 \%)$ & $93(10.64 \%)$ \\
\hline Total $(1786)$ & $97(5.43 \%)$ & $109(6.10 \%)$ & $178(9.97 \%)$ \\
\hline
\end{tabular}

Table (4): Residence distribution of Cryptosporidiosis.

\begin{tabular}{|l|l|l|l|}
\hline Residence Methods & Ziehl-Neelsen & Auramine & Coproantigen \\
\hline Urban (581) & $43(7.40 \%)$ & $40(5.88 \%)$ & $79(13.60 \%)$ \\
\hline Rural (1205) & $54(4.48 \%)$ & $69(5.73 \%)$ & $99(8.22 \%)$ \\
\hline Total (1786) & $97(5.43 \%)$ & $109(6.10 \%)$ & $178(9.97 \%)$ \\
\hline
\end{tabular}


Table (5): Co- existing of Cryptosporidium and other parasites.

\begin{tabular}{|c|c|c|}
\hline No. of parasites & $\begin{array}{l}\text { No. of patients } \\
\quad=109(\%)\end{array}$ & Other detected parasites \\
\hline Single & $66(60.55 \%)$ & - \\
\hline Mixed: & $43(39.45 \%)$ & - \\
\hline One parasite & $22(20.18 \%)$ & $\begin{array}{l}\text { - With Entameba histolytica (6) } \\
\text { - Isosopra(3) } \\
\text { - Chilomastix }(4) \\
\text { - Entrobious vermicularis(5) } \\
\text { - Hymenolepyis diminuta(1) } \\
\text { - Giardia lamblia }(1) \\
\text { - Blastocysts hominis(2) }\end{array}$ \\
\hline Two parasites & $11(10.09 \%)$ & $\begin{array}{l}\text {-With Giardia lamblia + Blastocysts } \\
\text { hominis(5) } \\
\text { - Strongyloides spp + Entameba histolytica (1) } \\
\text { - Blastocysts hominis + Giardia lamblia (5) }\end{array}$ \\
\hline More than two parasites & $10(9.17 \%)$ & $\begin{array}{l}\text {-With Hymenolepyis nana+ Giardia lamblia }+ \\
\text { Blastocysts hominis }(1) \\
\text { - Entrobious vermicularis }+ \text { Isospora }+ \\
\text { Endolimax nana(2) } \\
\text { - Isospora }+ \text { Chilomastix }+ \text { Myxoplus(3) } \\
\text { - Entameba histolytica }+ \text { Isospora+ } \\
\text { Chilomastix (4) }\end{array}$ \\
\hline
\end{tabular}

Table (6): Clinical presentations among patients.

\begin{tabular}{|c|c|}
\hline Clinical presentations & No $=\mathbf{6 6}(\mathbf{\%})$ \\
\hline Asymptomatic & $\mathbf{1 5}(\mathbf{2 2 . 7 3 \% )}$ \\
\hline Symptomatic & $\mathbf{5 1}(\mathbf{7 7 . 2 7} \%)$ \\
\hline Abdominal pain & $43(65.15 \%)$ \\
\hline Jaundice & $8(12.12 \%)$ \\
\hline Abdominal distension & $39(59.09 \%)$ \\
\hline Diarrhea & $42(63.64 \%)$ \\
\hline Signs & No=51(\%) \\
\hline Tender Abdomen & $44(86.27 \%)$ \\
\hline Hepatomegaly & $21(41.18 \%)$ \\
\hline Dehydration & $5(11.36 \%)$ \\
\hline Ascites &
\end{tabular}




\section{DISCUSSION}

In the present study, $97(5.43 \%)$ of the individuals were positive for Cryptosporidium spp. infection using ZiehlNeelsen $(\mathrm{Z} / \mathrm{N})$ stain, and by Auraminephenol stain, 109 (6.10\%) were positive. Using ELISA technique to detect Cryptocoproantigen infection was revealed in 178 (9.96\%). The difference was significant using $\mathrm{Z} / \mathrm{N}$, non significant using ELISA technique and Auramine stain. These results were in accordance with previous results by El-Shazly $\boldsymbol{e t}$ al . (2002) who diagnosed $C$. parvum in stool samples by $\mathrm{Z} / \mathrm{N}$ stain as $5.3 \%$ and ELISA as $8.3 \%$. Also, Helmy et al. (2014) detected that the prevalence of Cryptosporidium was 2.4, 6.7 and $49.1 \%$ in children using EIA, ICT and PCR, respectively. However, it was higher than Yilmaz et al. (2008) who recorded that only $1.95 \%$ of 2000 children were positive on microscopy of acid fast stained smears, and $4.9 \%$ were positive by ELISA. On the other hand, the present results were lower than Al-Shamiri et al. (2010) in Yemen who recorded that $34.7 \%$ were positive by microscopy, and $26.1 \%$ were positive by ELISA.

Among the centers examined, the highest infection prevalence recorded was in Talkha by $\mathrm{Z} / \mathrm{N}$, Auramine and Coproantigen detection respectively followed by Belqas, Aga and the lowest prevalence was detected in Mansoura center. However, non statistically significant difference of prevalence was detected among the centers .

Cryptosporidiosis recorded in the present study was relatively higher in the age group up to 5 years old by $\mathrm{Z} / \mathrm{N}$, Auramine and Coproantigen detection respectively. The prevalence was significantly higher using Ziehl-Neelsen stain, followed by Auramine stain and lastly by Coproantigen detection. The second group was $>5-20$ years, then the group $>40$ and lastly the group $>20-40$, by $\mathrm{Z} / \mathrm{N}$, Auramine and Coproantigen detection respectively. This agreed with a study in Zagazig (Egypt) by Abou-ElMagd and Abou-Shady (1986) who stated that cryptosporidiosis was more common in the age of 2-12 years old. Also, Al-Shamiri et al. (2010) stated that the highest rate of infection was observed in preschool age group between 2 - 6 years, and the highest percentage seroprevalence was observed among infant group. Youssef et al. (2008) detected an infection prevalence of $18.9 \%$ of children $<2$ years old. In Korea, also the peak of infection was in children aged 1-5 years (Casemore, 1990). Cryptosporidiosis occurs mainly in children aged 1-9 years, with the onset of infection peaking in the summer in association with communal swimming venues and recreational water use (Barry et al., 2013).

Outbreak investigations have also put into focus the role of food handlers as a source of food contamination and subsequent transmission of cryptosporidiosis (Robertson and Chalmers, 2013). Clinical infection is less common after the age of 40 years, and there is apparently no evidence of elevated incidence rates in the elderly (Casemore, 1988 and Abd Elkader et al., 2011). However, incidence in adults may increase dramatically during waterborne outbreaks of infection and, therefore, may provide an early indication 
of the likely route of transmission of Cryptosporidium to the community (Casemore, 1995).

Cryptosporidiosis was found to be relatively higher in females than males using Auramine stain with statistically significant difference results. However, using Coproantigen detection by ELISA was $10.64 \%$ and $9.32 \%$ in females and males respectively. The difference showed no statistical significance. This agreed with Park et al. (2006) who recorded that the infection reached $1.9 \%$ in females and $1.2 \%$ in males with no statistical difference. Also, Al-Shamiri et al. (2010) recorded that cryptosporidiosis was $36.2 \%$ in females and $32.7 \%$ in males. Abd-Al Kader et al. (2011) reported a slight increase of cryptosporidiosis infection in males $(5.1 \%)$ and in females (4. 9\%). Higher prevalence in females could be attributed to higher sample size of females in the study. This is on contrary to other studies that showed higher prevalence in males due to the presence of males in outdoor areas as farms, and contact with animals more than females. However, other studies suggested that distribution of cryptosporidiosis cases by sex indicates that males and females appear to be equally susceptible to infection (Fayer and Ungar, 1986).

The present study revealed that increased infection with cryptosporidiosis in rural areas were more than urban areas. the difference was significant using Auramine stain . Soliman (1992) detected a significant correlation between presence of animals and close contact with soil and Cryptosporidium spp. infection. The prevalence was $49.1 \%$ where $C$. hominis was dominated $(60.5 \%)$, followed by $\mathrm{C}$. parvum (38.3\%). Living in villages, drinking underground water and having contact with animals were risk factors (Fathy et al., 2014). Higher infection rates were found in children living in rural and semi-urban areas than in those residing in urban areas (Ghenghesh et al., 2012). Youssef et al. (2008) reported $54.3 \%$ of Cryptosporidium spp. cases who revealed a history of animal contact. In addition, Al-Shamiri et al. (2010) reported $43.6 \%$ of cases coming from rural areas, and $25.1 \%$ from urban areas. Residence in rural area appears to be a contributing factor to increase Cryptosporidium spp. infection risk with increased exposure to zoonotic infection from peridomestic animals (AbdelWahed, 1999 and Yu et al., 2004).

Mixed infection of Cryptosporidium spp. with other parasites was detected in about $39.45 \%$ of cases . Co-existing parasites varied between $H$. nana, $G$. lamblia, B. hominis, $E$. vermicularis, Isospora belli, Endolimax nana, Chilomastix mesnili, E. histolytica, and Strongyloides stercoralis. Mixed infection with one parasite was detected in $20.18 \%$, two parasites were detected in $10.09 \%$, and more than 2 parasites in $9.17 \%$.

Obiajuru et al. (2008), in Imo State, Nigeria, showed that most of the patients (74.04\%) had mixed infections with $E$. histolytica, G. lamblia and E. coli, while $10.90 \%$ had single infection of cryptosporidiosis. Certad et al. (2005) in Venezuela reported that $34 \%$ of Cryptosporidium-infected patients had mixed infections with other parasites, mostly with $B$. hominis in $19 \%$ and $S$. stercoralis in $7 \%$ of cases . 
In the present study, $15(22.73 \%)$ of the infected cases were asymptomatic, and $51(77.27 \%)$ were symptomatised. These results were in agreement with Kirkpatrick et al. ( 2008) who reported that in study on Ninety-six Bangladeshi children $(42.5 \%)$ were diagnosed with Cryptosporidium infection. A total of 51 (22.6\%) had asymptomatic infection, whereas $58(25.7 \%)$ had symptomatic cryptosporidiosis, of whom $17(29.3 \%)$ had recurrent disease. Also, Sajjad et al. (2014) showed in study in Pakistan on 105 patients with acute diarrhoea, Fifty three $(50.4 \%)$ were males. The mean age was $34 \pm 8.4$ years. Of $105,58(55 \%)$ patients had Cryptosporidium isolated in stool examination. Infected patients had statistically significant greater stool frequency per day, abdominal pain , vomiting, low grade fever, fatigue and dehydration and a shorter duration of illness with more watery diarrhea. Also, Mirzaei (2007) recorded $25.6 \%$ of cryptosporidiosis cases had diarrhea. According to Abd El-Messeh et al. (2005) vomiting and persistent diarrhea are important clinical findings associated with Cryptosporidium spp., and they need hospitalization. Hassan et al. (1995) recorded that $91.7 \%$ of children suffering from diarrhea were positive for Cryptosporidium coproantigen by ELISA.

The most frequently recognized clinical picture of cryptosporidiosis involves chronic watery diarrhea. However, asymptomatic infection is also relatively common. A nonspecific low-grade fever, malaise, anorexia, abdominal discomfort, and nausea may accompany the diarrhea. These symptoms, if chronic, can lead to weight loss, dehydration, and malnutrition. (Derouin et al., 2010).

\section{CONCLUSION}

There was a high prevelance of Cryptosporidium infection in the studied areas and must be taken in mind as a routine examination in all diarrhia samples especially in children .

\section{REFERENCES}

1. Abd El-Kader, N.M.; Blanco, M.A.; AliTammam, M.; Abd El Ghaffar, A.E.; Osman, A.; El Sheikh, N.; Rubio, J. M. and Fuentes, I. (2011): Detection of Cryptosporidium parvum and Cryptosporidium hominis in human patients in Cairo, Egypt. Parasitol Res., 110 : 161- 166.

2. Abd El-Messih, I.; Wierzba, T.; AbuElyazeed, R.; Ibrahim, A.; Ahmed, S.; Kamal, K.; Sanders, J. and Frenck, R. (2005): Diarrhea associated with Cryptosporidium parvum among young children of the Nile River delta in Egypt. J. Trop. Pediatr., 51:154-159.

3. Abd El-Wahed, M. M. (1999): Cryptosporidium infection among sheep in Qalubia Governorate, Egypt. J. Egypt Soc Parasitol., 29(1)113-8.

4. Abou-El-Magd, L.A. and Abou-Shady O. (1986): A preliminary study of human cryptosporidiosis. J Egyptian Soc Parasitol., 16: 573-7.

5. Al-Shamiri, A.H.; Al-Zubairy, A.H. and AlMamari, R.F. (2010): The Prevalence of Cryptosporidium spp. in Children, Taiz District, Yemen. Iranian J Parasitol., 5(2): 2632

6. Antonios, S.N.; Salem, S.A. and Khalifa, E.A. (2001): Water pollution is a risk factor for Cryptosporidium infection in Gharbia Governorate. J Egypt Soc Parasitol., 31 (3) :963- 964.

7. Areeshi, M., Beeching, N. and Hart, C. (2007): Cryptosporidiosis in Saudi Arabia and neighboring countries, Ann Saudi Med., 27: 325-332.

8. Banwat, E.B., Egah, D.Z., Audu, E.S., Onile, B.A. and Datong, P.R. (2004): Cryptosporidium infection in under nourished 
children with HIV/AIDS in Jos, Nigeria. Annal of African Medicine, 3(2): 80-82.

9. Barry, M.A., Weatherhead, J.E. and Hotez, P.J. (2013): Childhood parasitic infections endemic in the United States. Pediatr Clin North Am., 60:471-485

10. Bialek, A.J., Yes, N.J., Gazzard, B.G. and Easterbrook, P.J. (2002): The changing pattern of AIDS - defining illness with the introduction of (HMRT) in a London clinic. Journal infection, 42(2) 134-139.

11. Caccio, S.M. and Putignani, L. (2013): Epidemiology of human cryptosporidiosis. Pbl. Springer Vienna. chapter 2, pp.: 43-79

12. Casemore D.P. (1988): Human cryptosporidiosis. In Reeves D. Geddes A, eds. resent advances in infection. No. 3. pbl. Edinburgh, Scotland: Churchill Livingstone, pp. 209-236.

13. Casemore, D.P. (1990): Epidemiological aspects of human Cryptosporidiosis. Epidemiol Infect., (104): 1-28.

14. Casemore, D.P. (1995): The problem with protozoan parasites. In: Betts W.B., Casemore D.P. Fricker C, et al., eds. Protozoan parasites and water. Pbl.Cambridge, England: Royal Institute of Chemistry, pp.: 10-18.

15. Certad, G., Arenas-Pinto, A., Pocaterra, L., Ferrara, G., Castro, J., Bello, A. and Luznunez, F. (2005): Cryptosporidiosis in HIV-infected venezuelan adults is strongly associated with acute or chronic diarrhea. Am J Trop Med Hyg ., 73(1): 54-57.

16. Colford, J.S., Wade, T., Wright, C., Charles, S. and Eisenberg. J. (2005): A pilot randomized, controlled trial of an in-home drinking water intervention among HIV positive persons. J. of Water and Health, 3 (2) :173-184.

17. Derouin, F., Dutoit, F. and de Motibrison, F. (2010): Cryptosporidium laboratory-based surveillance for Cryptosporidium to France, 2006-2009. Euro Survedl., 15(33): 1964219649.

18. El-Shazly, A.M., Atta, M. and El-Meniawy M.A. (2002): The use of Ziehl-Neelsen stain, enzyme linked immunosorbent assay and nested polymerase chain reaction in diagnosis of cryptosporidiasis in immunocompetent and immunocompromised patients, J. Egypt. Soc. Parasitol., 32: 155 -166.

19. Fathy, M. M. , ABD EL-Razek, N.M., Hassan, F.A. and EL-Badry, A.A. (2014): Molecular copro-prevalence of Cryptosporidium in Egyptian children and evaluation of three diagnostic methods. Indian Pediatrics, 51 (15): 729-731.

20. Fayer, R., Morgan, U. and Upton, S. J. (2000): Epidemiology of Cryptosporidium transmission detection and identification. J. Prasitol., (30) : 1305-1322.

21. Fayer, R. and Ungar, B.L. (1986): Cryptosporidiosis spp. and Cryptosporidiosis, Microbiol Rev., (50): 458-483.

22. Garcia, M. S. (2007): Medical Diagnostic Parasitology. $7^{\text {th }}$ edition, pbl. ASM Press, Washington, USA, tissue and body fluids, chap. 2: 21-47.

23. Ghenghesh, K.S., Ghanghish, K. and ElMohammady H. (2012): Cryptosporidium in countries of the Arab world: the past decade (2002-2011). Libyan J Med., 7: 10-34.

24. Hassan, M., Atta, M., El-Meniawy, M.A., El-Mahrouky, F. and El-Mahrouky, L. (1995): Detection of Cryptosporidium antigen in stool samples among diarrheic children. J. Egypt. Soc. Parastol., (25): 599-606.

25. Helmy, Y.A., Krücken, J., N?ckler, K., Samson-Himmelstjerna, G. and Zessin, K.H. (2014): Comparison between two commercially available serological tests and polymerase chain reaction in the diagnosis of Cryptosporidium in animals and diarrheic children. Parasitol Res., 113(1):211-6.

26. Kirkpatrick, B.D., Haque, R. and Duggal, P. (2008): Association between Cryptosporidium infection and human leukocyte antigen class I and class II alleles. J Infect Dis., 197(3):474478 .

27. Markell, E., John, D. and Krotoski, W. (1999): Markell and Voge's Medical Parasitology. 8th Edition, pbl. Philadelphia: W.B. Saunders Company, pp.345-348.

28. Mirzaei, M. (2007): Prevalence of Cryptosporidium sp. infection in diarrhea and non- 
diarrheic humans in Iran. Korean J Parasitol., 45 (2): 133-143.

29. Obiajuru, I.O.C., Adogu, P.O.U. and Okechi, O. O. (2008): The prevalence of cryptosporidiosis and other intestinal protozoa infections among HIV patients in Imo State, Nigeria. Nigerian Journal of Parasitology, 29 [1] : 50-55.

30. Paik , G. (1980): Reagents , stains, and miscellaneous test procedures , pp. 1000-1024. In: Manual of clinical microbiology, $3^{\text {rd }}$ ed. American Society for microbiology , Washington.

31. Park, J.H., Guk, S.M ., Han , E.T , Shin, J.L and Chai, J.Y. (2006): Genotype analysis of Cryptosporidium infection in immunocompromised patients, J. Clin . Microbiol., 15:145154.

32. Paul, R. H. and Gordon, N. (2002): Epidemiology and clinical features of Cryptosporidium infection in lmmunocompromised patients. J. CIin.Microbiol., 15:145154.

33. Ridaly, D.S. and Hawgood, B. (1956): The value of formol- ether concentration of fecal cysts and ova. J . Clin. Pathol., 9 (1) : 74-76.

34. Robertson, L.J. and Chalmers, R.M. (2013): Foodborne cryptosporidiosis: is there really more in Nordic countries? Trends Parasitol., 29 (1):3-9.

35. Sajjad, A., Sunil, M., Kiran, K., Kapeel, R. and Shehla, B. (2014): Prevalence, clinical presentation and treatment outcome of cryptosporidiosis in immunocompetent adult patients presenting with acute diarrhea. J. Pak. Med Assoc., 64(6): 613-618.

36. Soliman N. (1992): Cryptosporidium infection among primary school children in a rural area in Alexandria. J Egypt Public Health Assoc., 67(3-4):501-19.

37. Xiao, L. (2010): Molecular epidemiology of cryptosporidiosis an update, Exp. Parasitol., 124 (1) 80 - 89

38. Yilmaz, H., Tas-Cengiz, Z. and Cicek, M. (2008): Investigation of cryptosporidiosis by enzyme-linked immunosorbent assay and microscopy in children with diarrhea. Saudi Med. J., 29(4): 526-529.

39. Youssef, F.G.; Adib, 1.; Riddle, M.S. and Seisle't, C.O. (2008): A review of cryptosporidiosis in Egypt. J. Egypt Soc Parasitol., 38 (1) : 9-28.

40. Yu J.R., Lee, J.K., Seo, M., Kim. S.I., Sohn, W.M., Huh, S., Choi, H.Y. and Kim, T.S. (2004): Prevalence of cryptosporidiosis among the villagers and domestic animals in several rural areas of Korea, Korean $\mathbf{J}$ Parasitol., 42 (1) :1-6. 


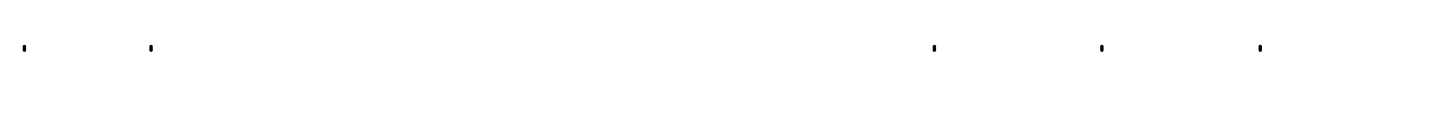

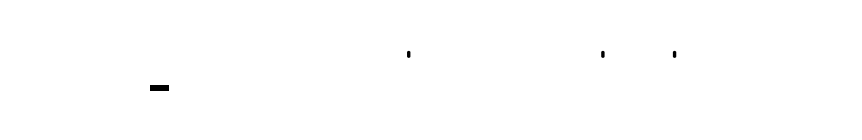

\author{
جمال على أبو شعيشع
}

قسم الطفيليات - كلية الطب -جامعة الأزهر

خلفية البحث : الكريبتوسبوريديوم هو طفيل حيواني المنشأ يصيب البشر عن طريق تتاول الأغذية أو المائ

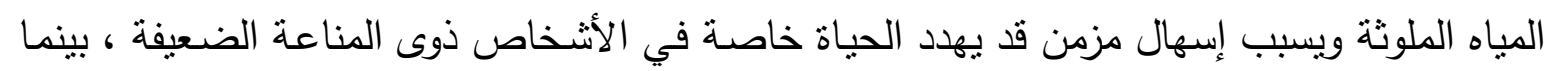

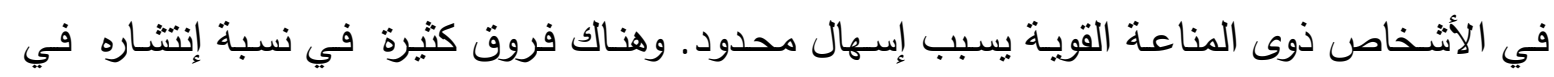

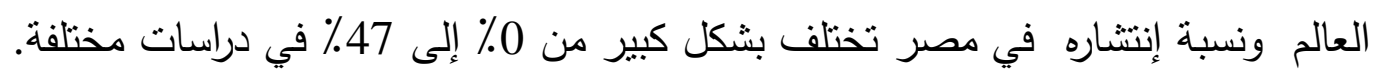

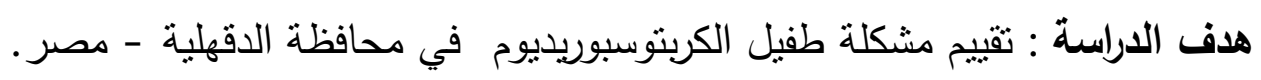

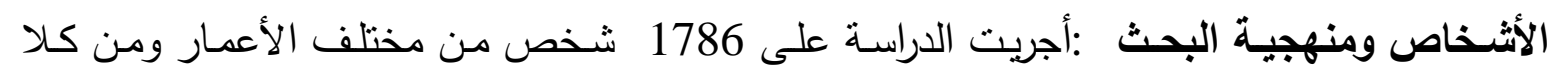

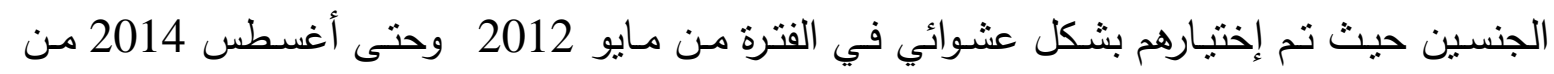

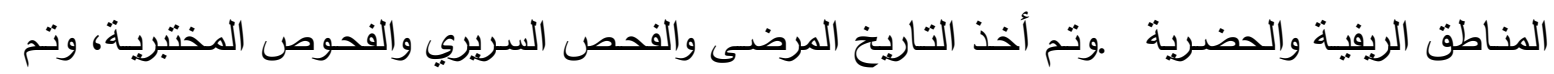

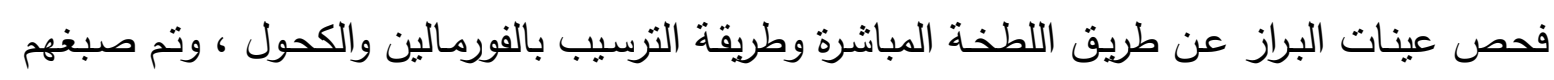

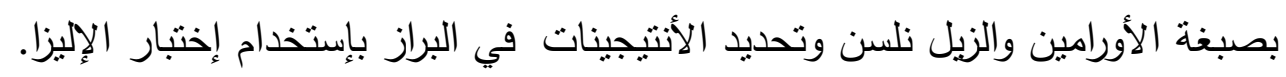

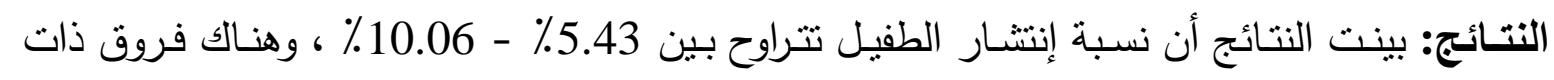

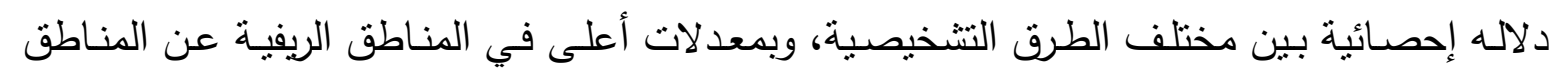

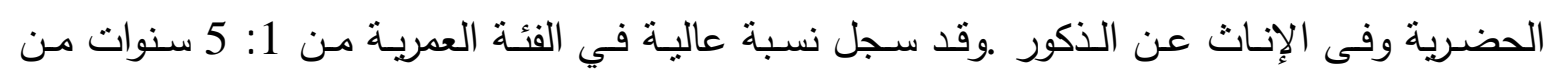

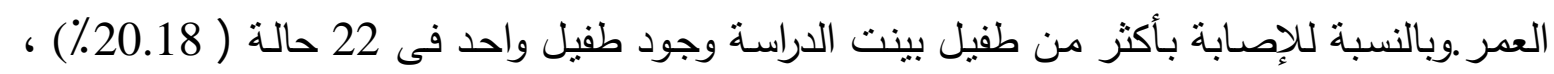

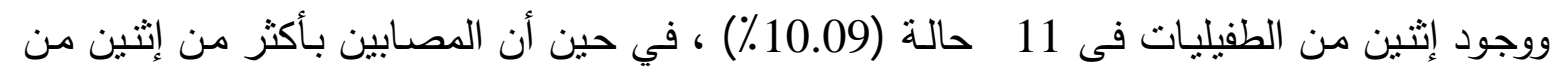

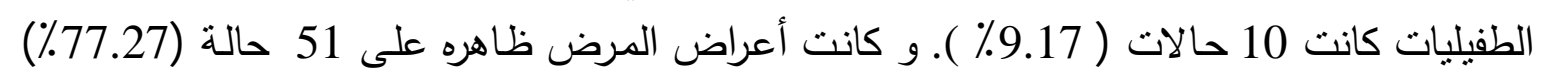

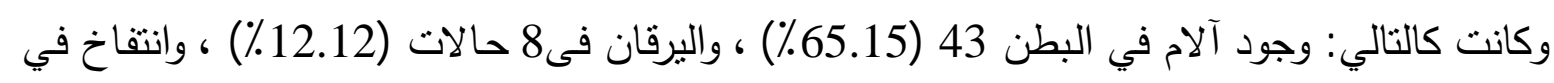

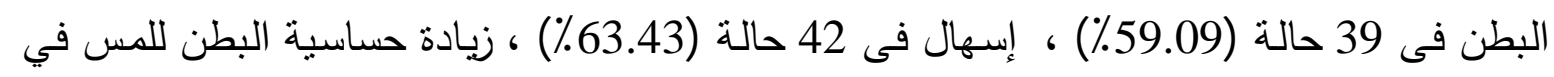

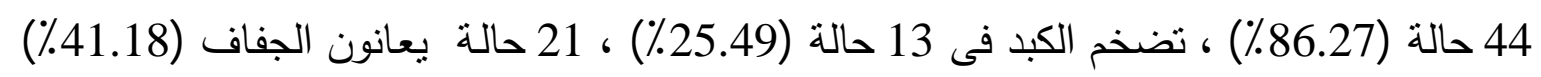
والذين يعانون من حالات الإستسقاء كانوا 5 حالات

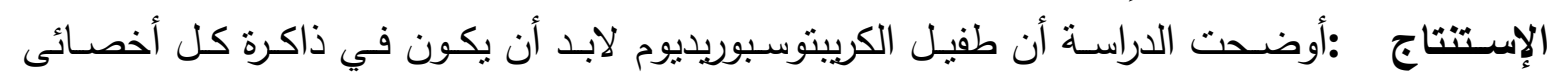

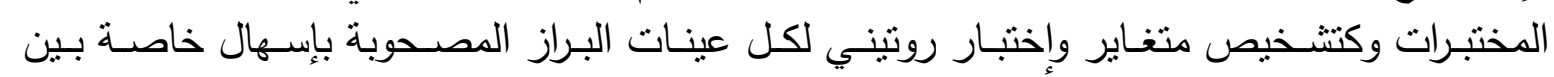

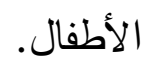

